\title{
AHP-based spatial analysis of water quality impact assessment due to change in vehicular traffic caused by highway broadening in Sikkim Himalaya
}

\author{
Polash Banerjee $^{1}$ (1) Mrinal Kanti Ghose ${ }^{2}$ (1) $\cdot$ Ratika Pradhan $^{3}$
}

Received: 2 November 2017 / Accepted: 4 April 2018 / Published online: 3 May 2018

(c) The Author(s) 2018

\begin{abstract}
Spatial analysis of water quality impact assessment of highway projects in mountainous areas remains largely unexplored. A methodology is presented here for Spatial Water Quality Impact Assessment (SWQIA) due to highway-broadening-induced vehicular traffic change in the East district of Sikkim. Pollution load of the highway runoff was estimated using an Average Annual Daily Traffic-Based Empirical model in combination with mass balance model to predict pollution in the rivers within the study area. Spatial interpolation and overlay analysis were used for impact mapping. Analytic Hierarchy ProcessBased Water Quality Status Index was used to prepare a composite impact map. Model validation criteria, cross-validation criteria, and spatial explicit sensitivity analysis show that the SWQIA model is robust. The study shows that vehicular traffic is a significant contributor to water pollution in the study area. The model is catering specifically to impact analysis of the concerned project. It can be an aid for decision support system for the project stakeholders. The applicability of SWQIA model needs to be explored and validated in the context of a larger set of water quality parameters and project scenarios at a greater spatial scale.
\end{abstract}

Keywords Analytic hierarchy process $\cdot$ Environmental impact assessment $\cdot$ Geographic information systems $\cdot$ Sensitivity analysis $\cdot$ Water pollution $\cdot$ Highway

Electronic supplementary material The online version of this article (https://doi.org/10.1007/s13201-018-0699-5) contains supplementary material, which is available to authorized users.

Polash Banerjee

banerjee.polash@gmail.com

Mrinal Kanti Ghose

mkghose@cus.ac.in

Ratika Pradhan

ratika.p@smit.smu.edu.in

1 Department of Computer Science and Engineering, SMIT, Sikkim Manipal University, Majitar, Sikkim 737136, India

2 Department of Computer Applications, Sikkim University, Gangtok, Sikkim 737102, India

3 Department of Computer Applications, SMIT, Sikkim Manipal University, Majitar, Sikkim 737136, India

\section{Introduction}

Highways are essential for the development and security of a region. However, understanding the detrimental effects of highway projects is pivotal for environmentally appropriate decision making. Environmental impact assessment (EIA) involves the assessment of impacts of a development project on the environmental attributes, including water resources (Barthwal 2012; Canter 1995). Conventional EIA can be time consuming, expensive, and subjective (Glasson et al. 2005; Takyi 2012). Moreover, conventional EIA focuses mainly on the temporal aspect of the impacts and undermines the importance of their spatial distribution. Geographic information systems (GIS) can overcome these limitations and provide an unbiased and easily interpretable EIA (Agrawal 2005).

A highway is essentially a non-point source of water pollution. Construction and post-construction conditions of a highway generate pollutants, which degrade the water quality and affect the habitat of the nearby water bodies (Wu et al. 1998). Highway runoff contains relatively high 
concentration of pollutants as compared to the adjacent river (USEP 1996; Bingham et al. 2002; Gan et al. 2008). Statistical models suggest that traffic volume, rainfall characteristics, highway pavement type, and properties of pollutants and seasons are important determinants of road runoff composition (Aldheimer and Bennerstedt 2003; Forsyth et al. 2006; Granato 2013; Kayhanian et al. 2003; Kim et al. 2006; Li and Barrett 2008; Pagotto et al. 2000; Tong and Chen 2002; USEP 1996; Yannopoulos et al. 2004, 2013). These models mostly cater to highway projects of developed countries. Applicability of these models in developing countries remains largely unexplored. Depending upon the nature of the highway runoff study, traffic volume can be considered in two broad ways, namely, as average daily traffic and vehicles during storm. Average daily traffic is a good predictor of water pollutants like Chemical Oxygen Demand (COD), Total Suspended Solids (TSS), and Zinc (Zn), while it poorly predicts the levels of lead, copper, and oil and grease (Thomson et al. 1997; Venner 2004). In contrast, oil and grease has a significant relationship with the vehicles during storm rather than average daily traffic (Stenstrom et al. 1982; Venner 2004). Correlation studies of river water have shown COD is strongly correlated topercent Dissolved Organic Carbon, Dissolved Oxygen, and Total Dissolved Solids (TDS). Moreover, TSS is strongly associated with pH and TDS (Bhandari and Nayal 2008; Waziri and Ogugbuaja 2010).

A wide variety of water quality indices are used in the impact assessment of a highway project. However, except for Water Quality Status Index (WQSI), all other water indices involve predetermined weight or the importance of water pollutants, which cannot be manipulated to see the impact of the change in water pollutant weight on the overall impact on water quality. (Karbassi et al. 2011; Mushtaq et al. 2015; Li et al. 2009; Yan et al. 2015). The weight of a pollutant can be determined using Multi-criteria Decision-Making (MCDM) methods like Delphi Method and Analytic Hierarchy Process (AHP) that use expert opinion-based criteria weighing (Mushtaq et al. 2015; Kumar and Alappat 2009). AHP decomposes the decision process into several levels of hierarchy. Based on a pairwise comparison of criteria for alternatives, a comparison matrix is made for the evaluation of criteria weights (Saaty 1980, 1990; Saaty and Vargas 1994). The data requirement for AHP is less data-intensive than classic statistical methods, which are based on historical data (Arriaza and Nekhay 2008). Use of AHP-based weighing of pollutants helps in giving due importance to the characteristics and conditions of the study area, which may not be reflected in non-expert opinion-based criteria weighing (Karbassi et al. 2011).

Limited literature is available on GIS-based water quality impact assessment of highway projects (Agrawal 2005; Banerjee and Ghose 2016; Brown and Affum 2002). These studies do not provide a clear methodology to perform Spatial Water Quality Impact Assessment (SWQIA). In addition, the reliability of these models is arguable as they lack appropriate model validation criteria. Moreover, none of them have discussed the importance of individual water pollutants on the overall value of a spatial water quality score or index. Spatial analysis of water quality usually involves interpolation of individual water pollutants in the study area, followed by combining their thematic maps using appropriate water quality index (Gajendra 2011; Yan et al. 2015; Zhou et al. 2007). Studies show that kriging is an effective interpolation method (Fallahzadeh et al. 2016; Ostovari et al. 2012; Sadat-Noori et al. 2014).

Spatial Explicit Sensitivity Analysis (SESA) is progressively becoming an essential component of spatial model validation. It is the measurement of variation in the model outputs explained by the variation in the model inputs (Chen et al. 2010, 2011; Crosetto et al. 2000; Feizizadeh et al. 2014; Lilburne and Tarantola 2009; Qi et al. 2013; Xu and Zhang 2013). The outputs of a robust spatial model show marginal perturbations to changes in the model inputs. However, the computational cost associated with SESA is a major constraint for its inclusion in spatial analysis.

The aim of this study is to address the lack of appropriate understanding and methods to assess the spatiotemporal impact of highway construction on water quality in a developing country. The SWQIA model performs a projectspecific spatiotemporal assessment of traffic-induced water pollution in East Sikkim. With further validation, in terms of a wider study area and comprehensive water quality parameters, it can be used in developing countries to assess impacts of highway construction on water quality. It acts as a geovisualization and temporal extrapolation tool for traffic-induced water pollution. Moreover, SWQIA model can capture people's perception of the project impacts. The results of the model are encouraging and show that it is a robust model with good prediction capability.

\section{Materials and methods}

\section{Study area}

The study area stretches from Rangpo $\left(27^{\circ} 10^{\prime} 31.26^{\prime \prime} \mathrm{N}\right.$, $88^{\circ} 31^{\prime} 44.43^{\prime \prime}$ E, Elevation $300 \mathrm{~m}$ ) to Ranipool ( $27^{\circ} 17^{\prime} 28.74^{\prime \prime}$ $\mathrm{N}, 88^{\circ} 35^{\prime} 31.11^{\prime \prime} \mathrm{E}$, Elevation $847 \mathrm{~m}$ ) in the East district of Sikkim, a stretch of $27 \mathrm{~km}$ along the route of NH 10 highway. It is the main route which connects Sikkim with the rest of India. In 2008-09, the broadening of NH 10 had commenced to promote defence and economic growth in Sik$\mathrm{kim}$. The highway has been broadened from its present width of 7-12 $\mathrm{m}$. This broadening of the highway will cause an increase in traffic volume. The project stretches from Sevok 
in West Bengal to North Sikkim. However, the road corridor chosen for the study is relatively much smaller than the actual stretch of the highway because of its relatively homogenous geography. A drainage area of $147 \mathrm{~km}^{2}$ was delineated to include all the micro-catchments providing runoff to the highway/rivers (Machado et al. 2017; Siqueira et al. 2017). Furthermore, the project impact area of $7.4 \mathrm{~km}^{2}$ was demarcated by merging $50 \mathrm{~m}$ buffers around the rivers and the highway. The rationale of considering the project impact area was based on the accessibility of the river water/ road runoff by the wildlife and humans living near the river/ highway (Antunes et al. 2001; Geneletti 2004). The study area has steep elevations, which is predominated by subtropical vegetation, interspersed with small human habitations, traditional farming areas, and towns like Rangpo, Singtam, and Ranipool. The highway closely follows river Teesta and Rani Khola (Fig. 1). It is also worth noting that Sikkim has high biodiversity and it is home to a large number of endemic species (Arrawatia and Tambe 2011). Moreover, it has a unique culture which gives high value to its natural resources. Therefore, unabated water pollution can severely affect the ecological and cultural sanctity of this area.

\section{Data collection}

Based on the changes in Annual Average Daily Traffic (AADT) and landuse \& landcover (LULC), three time frames were considered for the study, viz. the year 2004 as pre-project scenario, 2014 as project implementation scenario, and 2039 as post-project scenario (Fig. 3). The changes considered from 'pre-project' to 'project implementation' scenarios included changes in AADT and LULC. While only change in AADT was considered for 'post-project year' scenario. AADT for 'post-project year' scenario was calculated based on annual growth rates for traffic, provided by Border Roads Organization. LULC in 'pre-project' and 'project implementation' scenarios was estimated using satellite images, whereas such an estimation was not possible for 'post-project' scenario. Five water pollutants were considered for the study (Table 1) mainly based on the ability of the empirical model to predict their concentration in the road runoff, and second, on the availability of a complete data set of historical water quality of the rivers near the highway. Keeping in view of the ecological and cultural sensitivity of the local water bodies, drinking water quality standards of US Public Health Service (USPH 1962) were considered, except $\mathrm{pH}$, where Bureau of Indian Standards (BIS 2012) standard was considered for the present study. Various inputs for SWQIA model were prepared, as mentioned in Table 2.

\section{AHP model}

A structured questionnaire on pairwise comparison of water pollutants and project alternatives was administered to a panel of experts, based on a numerical scale having values ranging from 1 to 9 as suggested by Saaty (2000) (Table 3). The expert choice software was used for the preparation of comparison

Fig. 1 Study area

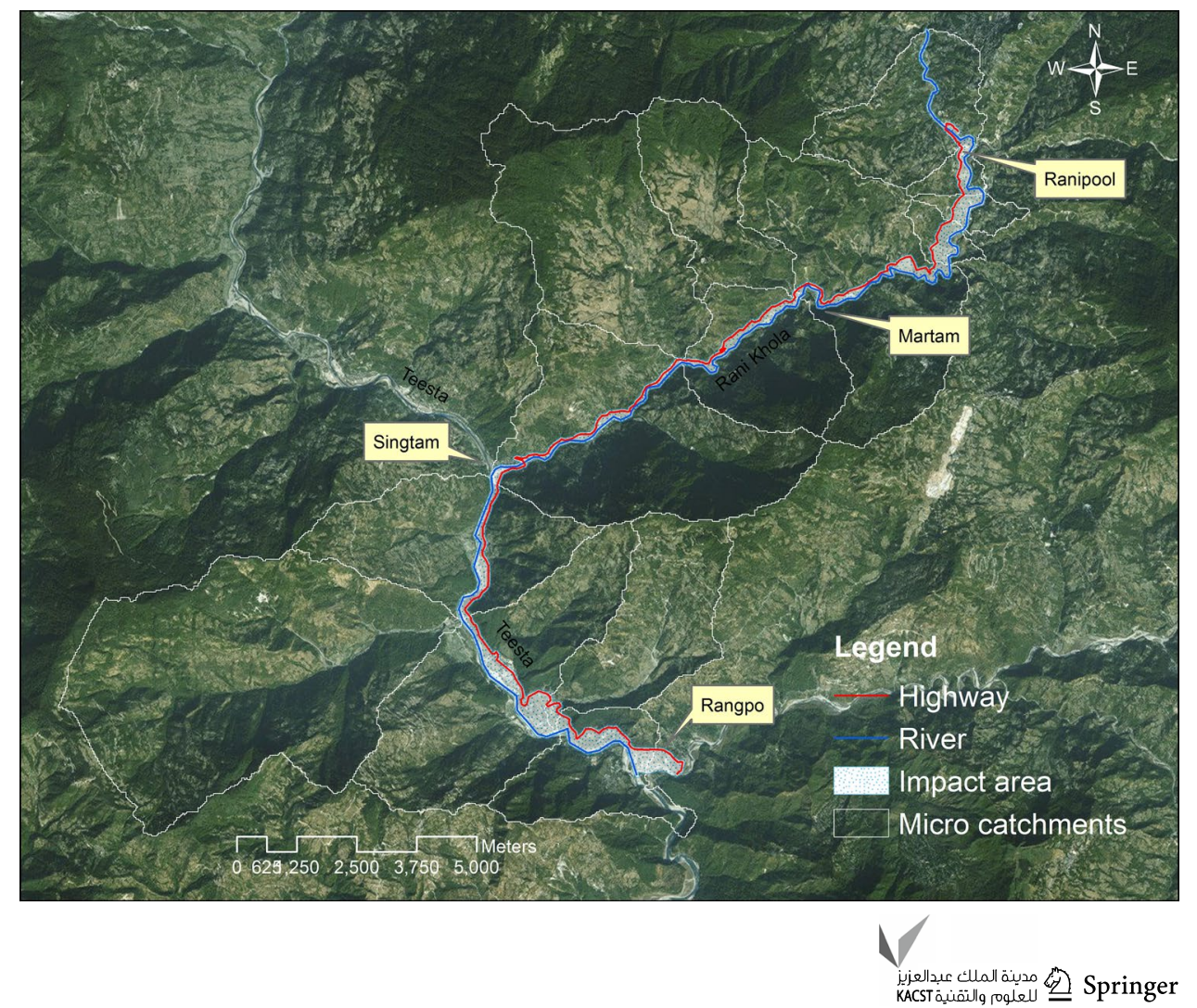




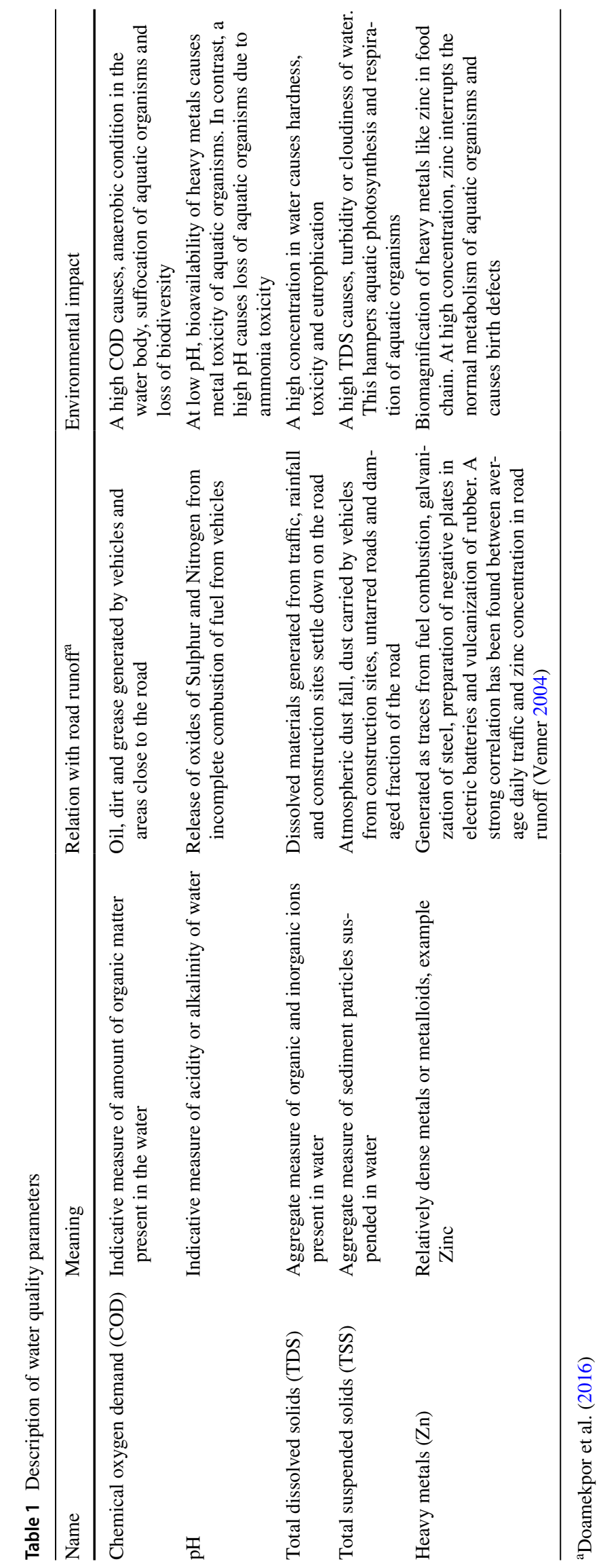


Table 2 Data types, source, and processing method for SWQIA model

\begin{tabular}{lll}
\hline Data type & Data source & Data processing \\
\hline AADT $^{\text {a }}$ & BRO, MoRTH & Direct input \\
DEM & bhuvan.nrsc.gov.in & Direct input \\
LULC $^{\text {b }}$ & Sikkim State Remote Sensing Applications Centre & Supervised image classification \\
Meteorological parameters & Rahman et al. (2012) & Direct input \\
Slope Percent & DEM from bhuvan.nrsc.gov.in & ArcGIS Spatial Analyst \\
Soil Texture & CISMHE (2008b) & Georeferencing, vectorization, rasterization \\
Water quality profile of Teesta and Rani & CISMHE (2008a) & Direct input \\
$\quad$ Khola rivers for year 2004 & & Direct input \\
Water quality profile of Teesta and Rani & Bhutia (2015), Gurung et al. (2015) & \\
Khola rivers for year 2014 & &
\end{tabular}

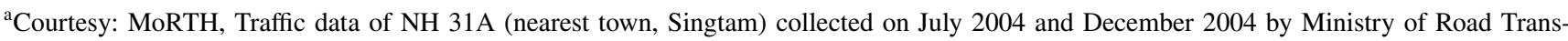
port and Highways, Govt. of India. Downloaded from http://morth.nic.in/writereaddata/sublinkimages/sikkim2987772247.htm accessed on 18/05/2014. BRO, Traffic data of NH 31A (nearest town, Rangpo) collected from 29/06/2012 to 06/07/2012 by Border Roads Organization, Govt. of India. The AADT was projected for 2014 and 2039 based on annual growth rates (in percent) for traffic estimated by BRO

b LISS III accessed from http://bhuvan.nrsc.gov.in/data/download/index.php under Resourcesat-I satellite image on 18/12/2014

Table 3 Importance scale used in AHP

\begin{tabular}{ll}
\hline Scale of importance & Description \\
\hline 1 & Both decision elements are equally important \\
3 & First element is slightly more influenced than the second \\
5 & First element is stronger than the second \\
7 & First element is significantly stronger than the second \\
9 & First element is extremely significant than second \\
$2,4,6,8$ & Judgement values between equally, slightly, strongly, very strongly and extremely \\
Reciprocals & When the $i$ th criterion is compared to the $j$ th criterion, $a_{i j}$, then $1 / a_{i j}$ is the judge- \\
& ment value when the $j$ th criterion is compared with the $i$ th, i.e., $a_{i j}=1 / a_{i j}$. \\
\hline
\end{tabular}

matrix and calculation of the weight of the pollutants. Two project alternatives were considered for the AHP model, viz. 'with project' and 'without project', for comparison of the impacts. The 'with project' alternative assumed that the highway had been broadened and traffic volume had increased, while 'without project' alternative assumed no change in the highway width and the traffic volume remains unchanged. In AHP, the elements of the comparison matrix, $a_{i j}>0$, express the expert's evaluation of the preference of the $i$ th criterion in relation with the $j$ th. It is worth noting that $a_{i j}=1$ whenever $i=j$ and $a_{i j}=1 / a_{j i}$ for $i \neq j$. The total number of pairwise comparisons by expert is $n(n-1) / 2$, where ' $n$ ' is the total number of criteria under consideration. The eigenvector, $\mathbf{w}$, matching the maximum eigenvalue, $\lambda_{\max }$, of the comparison matrix is the preferred solution of the AHP model, that is

$\mathbf{A} \mathbf{w}=\lambda_{\max } \mathbf{w}$.

or

$\left(\begin{array}{ccc}a_{11} & \cdots & a_{1 n} \\ \vdots & \ddots & \vdots \\ a_{n 1} & \cdots & a_{n n}\end{array}\right)\left(\begin{array}{c}w_{1} \\ \vdots \\ w_{n}\end{array}\right)=\lambda_{\max }\left(\begin{array}{c}w_{1} \\ \vdots \\ w_{n}\end{array}\right)$ where $\mathbf{A}$ is the comparison matrix. The elements of $\mathbf{w}$ must fulfill the condition, $\sum_{i=1}^{n} w_{i}=1$, and under ideal condition, $\lambda_{\max }=n$. The reliability of the AHP model is assessed by consistency ratio, $\mathrm{CR}=\mathrm{CI} / \mathrm{RI}$, where Consistency Index, $\mathrm{CI}=\left(\lambda_{\max }-n\right) /(n-1)$, and Random Consistency Index, $\mathrm{RI}$, that is obtained by a large number of simulation runs. It varies upon the order of the comparison matrix (Saaty 2000; Taha 2010). An inconsistency value not more than 0.1 is acceptable for an AHP model.

\section{Modelling of seasonal peak storm runoff}

Rainfall occurs almost the entire year in Sikkim (IMD 2014). However, there is a substantial drop in rainfall in the non-monsoon months, which is from November to March. While April-October gets a relatively high proportion of annual average rainfall (Rahman et al. 2012). Thereby, the non-monsoon months were considered as antecedent dry period and the highest daily rainfall was considered as maximum intensity rainfall. The drainage area and micro-catchments feeding the road runoff/rivers in the study area were 


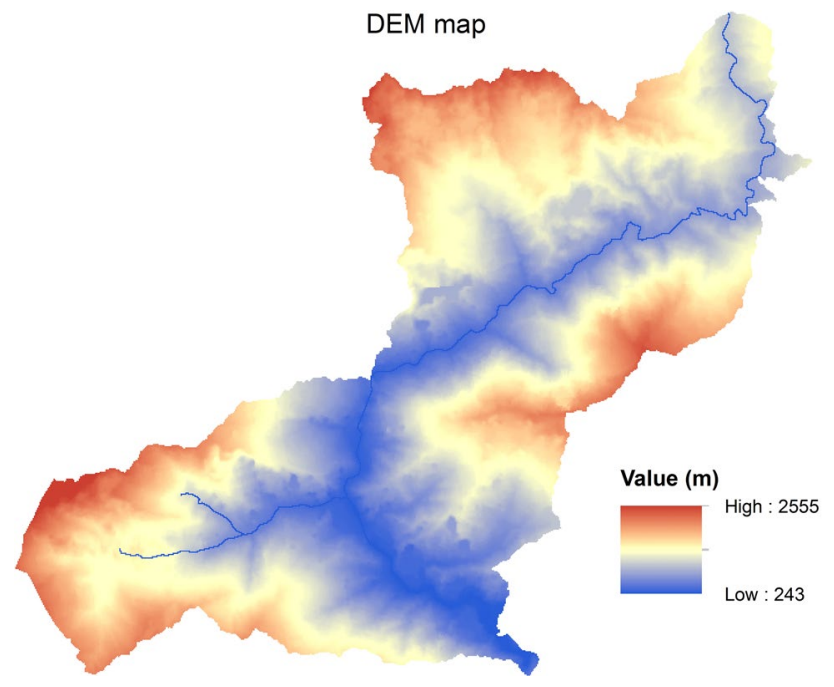

Fig. 2 Digital elevation model of the study area

demarcated using Digital Elevation Model (DEM) (Machado et al. 2017; Siqueira et al. 2017) (Fig. 2). HEC-GeoHMS, a geospatial hydrological extension of ArcGIS, was used to prepare Soil Conservation Service-Curve Number (SCSCN) maps for 'pre-project and project implementation' scenarios (Merwade 2012; Flemming and Doan 2013). For this, satellite images from LISS III were converted to LULC rasters using maximum likelihood method under image classification extension of ArcGIS (Fig. 3a, b). LULC rasters were reclassified into water, agriculture, forest, and medium residential areas. Furthermore, soil texture map of the drainage area was prepared from secondary sources (CISMHE 2008b) (Fig. 4). It was further reclassified into Hydrologic Soil Groups (HSG), based on the soil texture types (USDA 2007). CN maps were used to prepare Maximum recharge capacity maps ( $S$ Maps) based on the relation:

$S=\frac{25400}{\mathrm{CN}}-254$.

Runoff from each micro-catchment was estimated using the relation:

$Q=\left\{\begin{array}{ll}0 & \text { if } P<0.2 \times S \\ \frac{(P-0.2 \times S)^{2}}{P+0.8 \times S} & \text { if } P \geq 0.2 \times S\end{array}\right.$,

where $Q$ is the runoff and $P$ is the maximum intensity rainfall (Vojtek and Vojteková 2016).

\section{Multiple linear regression model for traffic-induced water pollution}

The empirical model developed by Kayhanian et al. (2003) was used in calculating the traffic-induced water pollutants
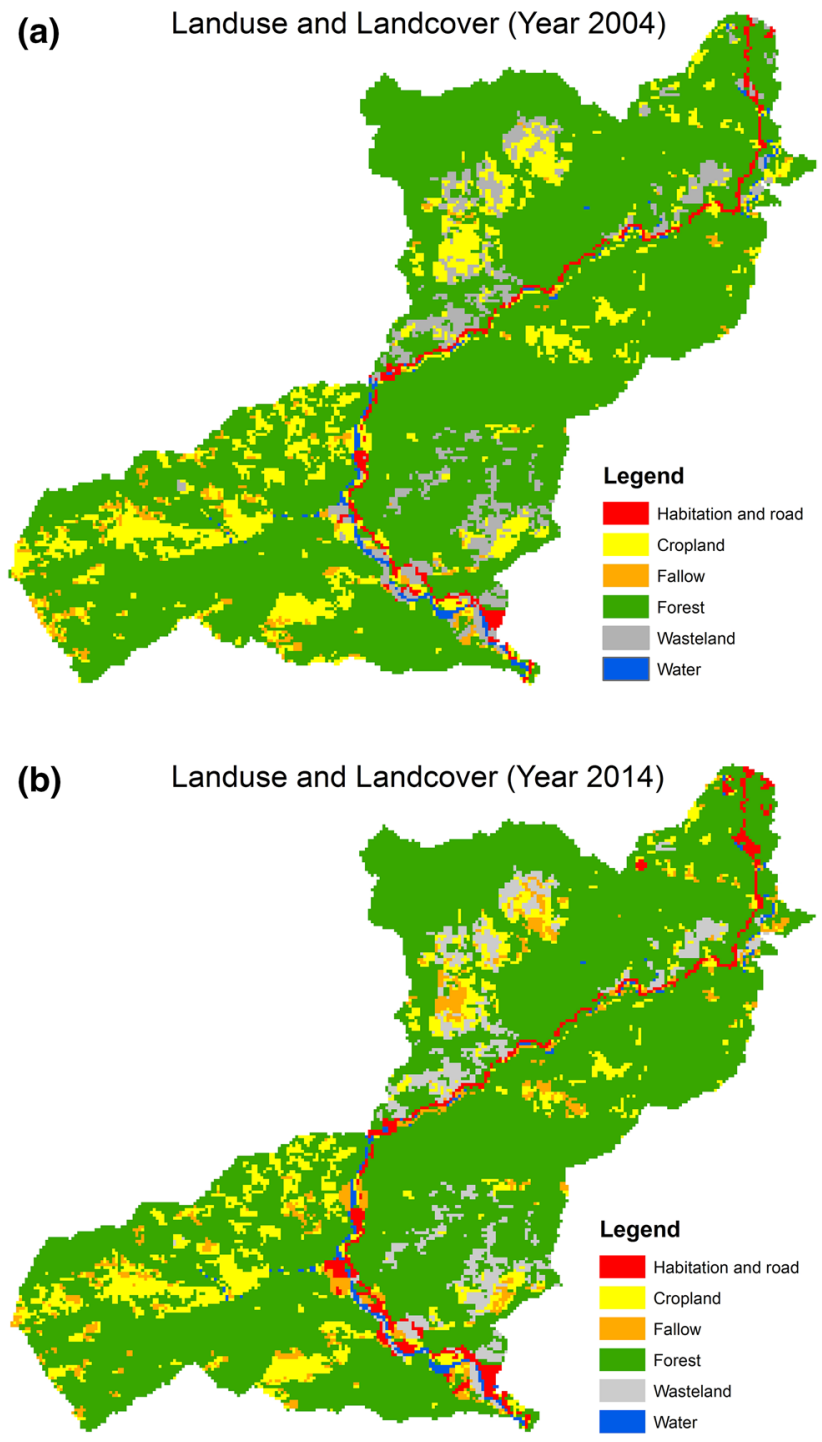

Fig. 3 Landuse and Landcover map of a pre-project scenario (2004) and $\mathbf{b}$ project implementation scenario (2014)

concentration in the highway runoff (Eq. 5). It is reliable in predicting road runoff concentration of conventional water pollutants like COD, pH, TSS, and TDS, while it is unable to predict turbidity and dissolved oxygen:

$C_{i}^{\mathrm{H}}=\exp \left(b_{i}+\sum_{j=1}^{6} a_{j} x_{j}\right)$,

where $C_{i}^{\mathrm{H}}$ is the concentration in the highway $H$ and $b_{i}$ is the $y$-intercept of the $i$ th water pollutant, $a_{j}$ is the proportionality coefficient, and $x_{j}$ is value of the $j$ th predictor variable. The predictor variables include Event Rainfall as $x_{1}$, Maximum Intensity Rainfall as $x_{2}$, Antecedent Dry Period as $x_{3}$, Cumulative Seasonal Rainfall as $x_{4}$, watershed area as $x_{5}$, 


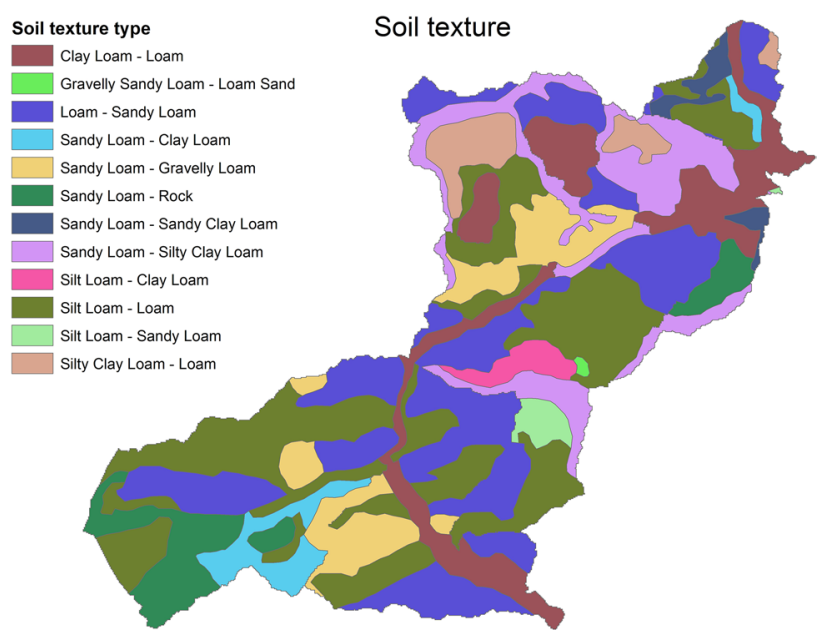

Fig. 4 Soil texture map

and AADT as $x_{6} . a_{j}$ is the coefficient of $x_{j}$. However, for the year 2039, except for AADT, the values of all other predictor variables were not available. As a result, the most reliable estimate of water pollutants given by Kayhanian et al. (2003) for $\mathrm{AADT}>30,000$ was considered for the year 2039.

\section{Estimation of water pollutant concentration in the project impact area using mass balance model}

The concentration of water pollutants due to traffic-induced pollution at various locations of the rivers within the project impact area was estimated using the mass balance model (Barthwal 2012; Davie 2008):

$C_{i}^{\mathrm{R}}=\frac{Q_{\mathrm{D}} C_{i}^{\mathrm{H}}+\sum_{j=1}^{n} Q_{j} C_{i j}}{Q_{\mathrm{D}}+\sum_{j=1}^{n} Q_{j}}$,

where $C_{i}^{\mathrm{R}}$ is the downstream concentration of the $i$ th water pollutant in the river, $Q_{j}$ and $C_{i j}$ are the upstream discharge rate in $1 / \mathrm{s}$ and concentration of the $i$ th water pollutant in $\mathrm{mg} / \mathrm{l}$ for the $j$ th stream or river. The runoff from the microcatchment area, $Q_{D}$, was calculated using SCS-CN method (Eqs. 3 and 4). The concentration of the water pollutant in the highway runoff, $C_{i}^{\mathrm{H}}$, was calculated using empirical model (Eq. 5). The concentration of water pollutant $C_{i}^{\mathrm{R}}$ at Rangpo was taken as the model output and it was compared with the observed data using model validation criteria. (Paliwal and Srivastava 2014). A correlation matrix of water pollutants estimated by the mass balance model was used to assess their nature of association.

\section{Preparation of water quality status index maps}

The project impact area map was overlaid upon the microwatershed map and 100 random points were created within the project impact area. These points were populated with concentration of water pollutants of various years derived from mass balance model as attributes. The attributes of these points were based on their position with respect to the micro-watershed feeding their runoff to the rivers. These points were considered as known points for spatial interpolation of pollutant concentrations over the project impact area.

Empirical Bayesian Kriging (EBK) is a robust and straightforward spatial interpolation technique. Unlike other types of kriging, EBK considers uncertainty in spatial parameters. The algorithm behind EBK generates several semivariogram models to minimize the prediction error generated from the uncertainty of model parameters. Each semivariogram gets a weight, based on Bayes' rule, which predicts how likely the observed data can be generated from a semivariogram (Banerjee et al. 2016; Cui et al. 1995; Krivoruchko 2012; Pilz and Spöck 2008). Hence, EBK was used for spatial interpolation of the water pollutants. Cross-validation criteria were used to assess the quality of spatial model made from the spatial interpolation. Mean Standardized Error and Standardized Root Mean Square Error were used as cross-validation criteria for the interpolation of the year 2014 (Chang 2017; Lloyd 2009). Pollutant maps prepared from spatial interpolation were converted to Single Factor Pollution Index (SFPI) maps using Eq. 6:

$P_{i j k}=\frac{C_{i j k}}{S_{j}}$

where $P_{i j k}$ is the SFPI value and $C_{i j k}$ is the measured concentration at the $i$ th location for the $j$ th water pollutant of the $k$ th year. $S_{j}$ is the standard value of the $j$ th water pollutant. The SFPI maps were further reclassified based on Table 4 .

$P_{i j k}<1$ is an indication of low pollution level, while $P_{i j k}>1$ indicate moderate-to-high pollution level depending on how low or how high the SFPI value is from one ( $\mathrm{Li}$ et al. 2009; Yan et al. 2015). The reclassified SFPI maps were used to prepare WQSI maps for various years using the relation:

$\operatorname{WQSI}_{i j k}=\frac{\sum_{j=1}^{n} W_{j} P_{i j k}}{\left[\sum_{j=1}^{n} W_{j} P_{i j k}\right]_{\max }}$,

Table 4 Standard of SFPI

\begin{tabular}{|c|c|c|c|c|c|}
\hline$P_{i}$ & $\leq 0.4$ & $0.4 \sim 1.0$ & $1.0 \sim 2.0$ & $2.0 \sim 5.0$ & $>5.0$ \\
\hline Pollution levels & Not-polluted & Slight polluted & Medium polluted & Heavy polluted & Serious polluted \\
\hline
\end{tabular}


where $W_{j}$ is the weight of the water pollutant calculated from AHP model and $P_{i j k}$ is calculated from Eq. 7. $\left[\sum_{j=1}^{n} W_{j} P_{i j k}\right]_{\max }$ is the maximum value in the set of $W_{j} P_{i j k}$. The WQSI varies from 0 to 1 . A WQSI value close to zero indicates no impact, while a value close to 1 implies high adverse impact. The WQSI was further reclassified using natural break classification (Table 5) (Mushtaq et al. 2015).

\section{Spatially explicit sensitivity analysis}

SA of project alternatives was done with respect to change in water pollutant weight for the AHP model. 'One-At-a-Time' is a relatively simple SA method, which mainly involves changing one input variable at a time to see its effect on the model output. Its major limitation is that it does not capture the effect of simultaneous variation of input variables on the model output (Murphy et al. 2004). OAT-based SESA was performed on WQSI of the year 2014 as a case study, by changing the water pollutant weight. The water pollutant weight was changed for a range of $\pm 20 \%$ with a step size of $\pm 2 \%$ for each water pollutant considering a uniform probability distribution within a range of $0-1$. The WQSI run maps were generated using Eq. 9:

$$
\mathrm{WQSI}_{t \alpha}=\frac{W_{t} P_{i t}+\sum_{j \neq t}^{n}\left(1-W_{t}\right) \frac{W_{j}}{\sum_{j \neq t}^{n} W_{j}} P_{i j}}{\left[W_{t} P_{i t}+\sum_{j \neq t}^{n}\left(1-W_{t}\right) \frac{W_{j}}{\sum_{j \neq t}^{n} W_{j}} P_{i j}\right]_{\max }},
$$

Subject to the condition:

$$
\sum_{j=1}^{n} W_{j}=1
$$

where $\mathrm{WQSI}_{t \alpha}$ is dependent on the $t$ th water pollutant and step size, $\alpha . W_{t}$ is the changed weight, and $\left(1-W_{t}\right) \frac{W_{j}}{\sum_{j \neq t}^{n} W_{j}}$ is the adjusted weight for the $j$ th water pollutant. Other variables hold the same meaning, as given in Eqs. 6, 7, and 8 (Chen et al. 2011; Xu and Zhang 2013). To evaluate the change in the WQSI value per pixel per step size, a change function was used:

$\mathrm{CR}_{\mathrm{it} \alpha}=\frac{\mathrm{WQSI}_{\mathrm{it} \alpha}-\mathrm{WQSI}_{\mathrm{it} 0}}{\mathrm{WQSI}_{\mathrm{it} 0}} \times 100$,

where $C R_{i t \alpha}$ is the change rate of WQSI at the $i$ th location for the $t$ th WQI at the $\alpha$ th step size. Mean Absolute Change Rate
(MACR), a summary sensitivity index, was used to assess the overall sensitivity of the entire study area with change in water pollutant weight:

$\mathrm{MACR}_{t \alpha}=\frac{1}{N} \sum_{i=1}^{N}\left|\frac{\mathrm{WQSI}_{\mathrm{it} \alpha}-\mathrm{WQSI}_{\mathrm{it} 0}}{\mathrm{WQSI}_{\mathrm{it} 0}}\right| \times 100=\frac{\mathrm{CR}_{\mathrm{it} \alpha}}{N}$,

where $M A C R_{t \alpha}$ is the mean absolute value of change rate of WQSI value due to change in the weight of water pollutant and $N$ is the total number of pixels. Equation 11 was also used to assess the temporal change in WQSI over various project scenarios. $M A C R_{i \alpha} \geq \alpha$ indicate that the SWQIA model is sensitive to the $i$ th water pollutant weight at the $\alpha$ th step size, while $M A C R_{i \alpha}<\alpha$ implies an insensitivity. In other words, if a change of say $\pm 10 \%$ of a model input brings $a \geq 10 \%$ change in model output, the MACR curve slope will be $\geq 45^{\circ}$. In such cases, the model will be considered as sensitive to the model input (Longley et al. 2010). The overall methodology is illustrated in Fig. 5.

\section{Results}

\section{AHP weight of water pollutants}

The order of AHP weight was found to be: $\mathrm{Zn}>\mathrm{COD}>\mathrm{TSS}>\mathrm{TDS}>\mathrm{pH}$. The inconsistency value of the AHP model was within acceptable limit $(\mathrm{CR}=0.01<0.1)$ (Table 6). The analysis showed that the 'with project' alternative had a higher priority of 0.727 as compared to the "without project' alternative priority score of 0.273 . Moreover, the project alternatives, viz. 'with project' and 'without project', did not change the order of priority level at various OAT weight change combinations in a range of $\pm 20 \%$. This proved that the alternatives were insensitive to the water pollutant weight, as each instances of weight change did not yield an equal or above change in the project alternatives (Banerjee and Ghose 2017; Longley et al. 2010). Thereby, the AHP model was robust.

\section{Runoff estimation, outputs of mass balance model, and thematic maps of water pollutants}

$\mathrm{CN}$ maps for pre-project and project implementation scenarios were used to estimate runoff from the micro-catchments (Fig. 6a, b). Water pollutants generated at various sections of the highway intersecting with various micro-catchments were estimated using Empirical model (Supplementary Figure S1,
Table 5 Impact category of WQSI

\begin{tabular}{lllll}
\hline Range & $\leq 0.55$ & $0.55 \sim 0.70$ & $0.70 \sim 0.85$ & $>0.85$ \\
\hline Pollution levels & No impact & Slight adverse impact & Moderate adverse impact & High adverse impact \\
\hline
\end{tabular}




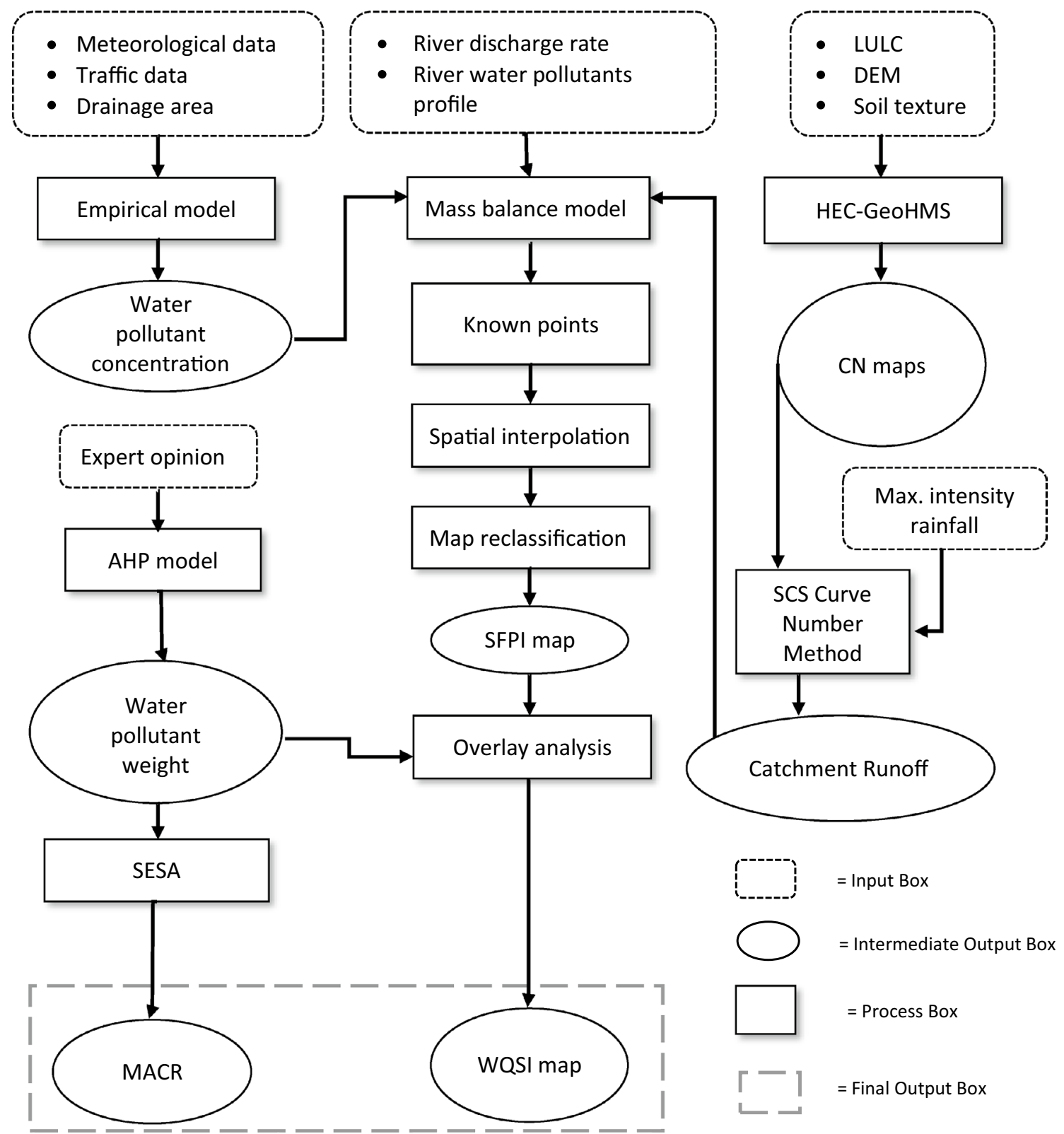

Fig. 5 Flowchart of spatial water quality impact assessment model

Table 6 HP weight

\begin{tabular}{llllll}
\hline Parameter & COD & $\mathrm{pH}$ & TDS & TSS & Zn \\
\hline Weight & 0.197 & 0.161 & 0.150 & 0.163 & 0.329 \\
\hline
\end{tabular}

Tables S1-S3). The outputs of the Empirical model, rivers discharge rates and their pollutant profiles (Supplementary Table S4) were fed into the Mass balance model. The contribution of pollution load from the highway runoff along each micro-catchment was then estimated (Supplementary Tables S5-S7). Traffic-induced water pollution contributed significantly to the water quality along the Rani Khola impact area as compared to nominal contribution along the Teesta area (Supplementary Tables S8-S10). The pollutants concentration estimated by mass balance model was compared with the downstream water pollutant profile at Rangpo for model validation (Supplementary Table S11). The model validation criteria showed satisfactory results (Table 7). The correlation matrix of water pollutants for 2004 showed a significant relationship between all the water pollutants. TDS had a moderate correlation with TSS and Zn. In 2014, except for Zn, the remaining water pollutants, namely, COD, $\mathrm{pH}$, TDS, and TSS, showed strong association amongst each other (Table 8). 


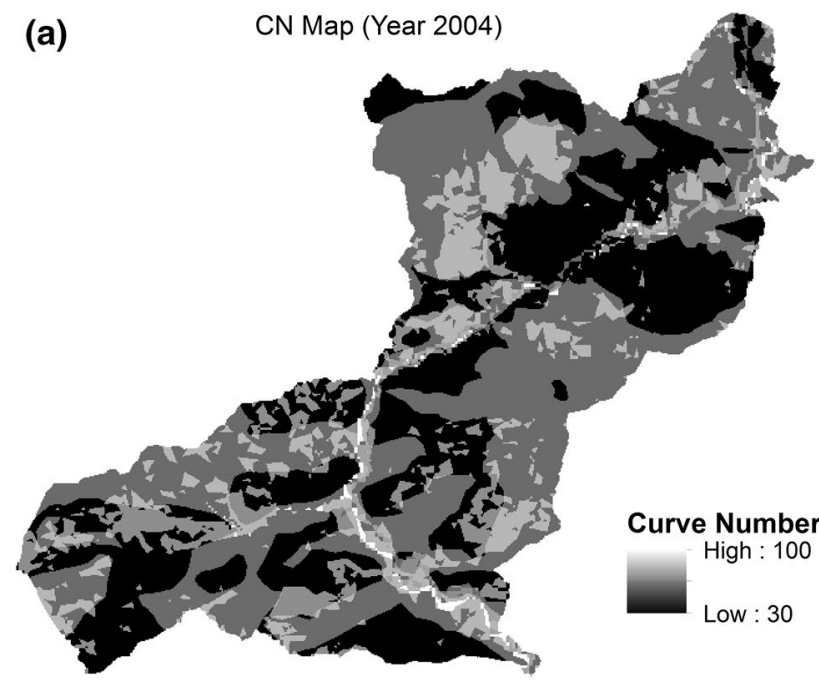

(b) $\quad$ CN Map (Year 2014)

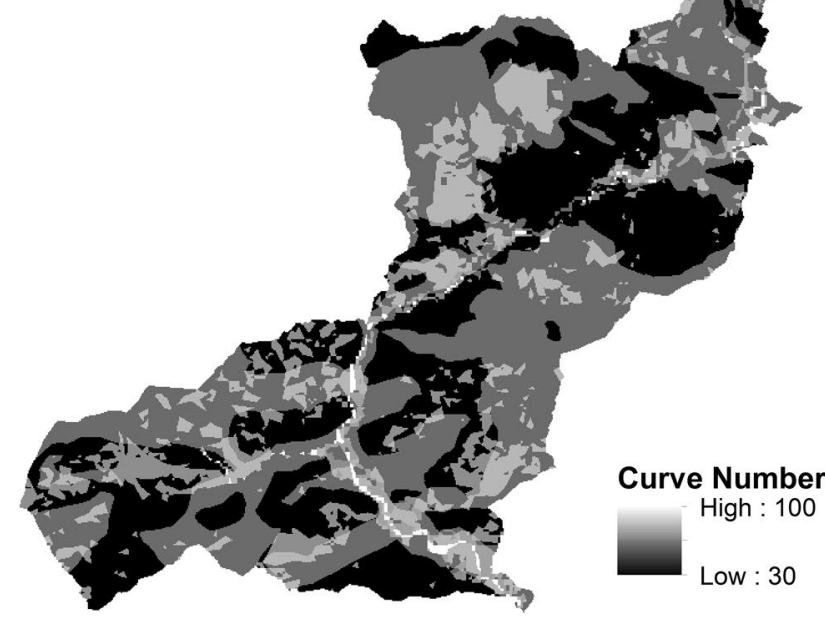

Fig. 6 a SCS-CN map of pre-project scenario (2004). b SCS-CN map of project implementation scenario (2014)

Table 7 MBM validation criteria

\begin{tabular}{lllll}
\hline Criterion & Fractional bias & $\begin{array}{l}\text { Normalized } \\
\text { mean square } \\
\text { error }\end{array}$ & $\begin{array}{l}\text { Correlation } \\
\text { coefficient }\end{array}$ & $\begin{array}{l}\text { Index of } \\
\text { agree- } \\
\text { ment }\end{array}$ \\
\hline Ideal value & 0 & 0 & 1 & 1 \\
Result & 0.003 & 0.041 & 0.997 & 0.961 \\
\hline
\end{tabular}

Cross-validation criteria showed satisfactory results for EBK interpolation (Table 9). SFPI maps of water pollutants showed a sharp change in concentration at three locations viz. Ranipool, Martam, and Singtam. Under 2004 and 2014 scenarios, COD maps showed heavy pollution along Rani Khola and seriously polluted condition along Teesta. However, for 2039 scenario, except for impact area above
Ranipool, the entire impact area was seriously affected due to COD pollution (Fig. 7a). pH maps of 2004 showed slight pollution all over the project impact area. In contrast, in 2014 and 2039, the impact area along Rani Khola showed slight pollution, while moderate pollution along Teesta (Fig. 7b). TDS in all scenarios remained at a Not-polluted level (Fig. 7c). On the other hand, TSS levels under 2004 and 2014 scenarios remained largely under seriously polluted level except for an upper fraction of the impact area up to Martam. Furthermore, under 2039 scenario, almost the entire impact area was seriously polluted under TSS pollution (Fig. 7d). Zn level under all the scenarios was within the not-polluted level (Fig. 7e).

\section{WQSI maps}

High adverse impact due to water pollution was observed from Martam all the way to Rangpo under 2004 and 2014 scenarios. While the remaining fraction of the impact area above Martam suffered a moderate adverse impact. Under 2039 scenario, almost the entire impact area had a high adverse impact, except for the impact area above Ranipool which had a moderate adverse impact (Fig. 8). Change in WQSI value from 2004 to 2014 showed marginal change of $5 \%$ occurred along Teesta, while no change occurred along Rani Khola area. In contrast, a substantial change in WQSI value from 2004 to 2039 occurred in the entire impact area, except for few pockets of no change in WQSI value. The changes were most prominent along the Rani Khola impact area. Comparing WQSI value from 2039 with 2014, significant change in WQSI was observed along Rani Khola, with 19\% change from Ranipool to Martam, while 12\% change from Martam to Singtam (Fig. 9).

\section{Spatially explicit sensitivity analysis}

MACR of WQSI over the change in water pollutant weights showed an approximately linear curve with varied slopes and intercept at zero. Second, MACR curves showed symmetry over $y$-axis, implying that the absolute value of change rate is the same for equal and opposite change in water pollutant weights. Slopewise the order of water pollutants was found to be, $\mathrm{Zn}>\mathrm{COD}>\mathrm{TSS}>\mathrm{TDS}>\mathrm{pH}$, implying that the sensitivity of WQSI to water pollutant weights was in harmony with the order of AHP weights (Fig. 10). Moreover, the slopes of sensitivity were much flatter indicating a low sensitivity of WQSI to change in water pollutant weights.

Figure 11 illustrates the locationwise change rate of the WQSI value of project implementation scenario at $16 \%$ increase of all the water pollutant weights. Change in COD and TSS weights led to a slight rise in WQSI value all along the project impact area. A greater change was observed 
Table 8 Correlation matrix of water pollutants under 'without'- and 'with'-project scenarios $(n=14)$

\begin{tabular}{|c|c|c|c|c|c|c|c|c|c|c|}
\hline & COD (2004) & COD (2014) & pH (2004) & pH (2014) & TSS (2004) & TSS (2014) & TDS (2004) & TDS (2014) & $\mathrm{Zn}(2004)$ & $\mathrm{Zn}(2014)$ \\
\hline COD & 1 & 1 & 0.900 & 0.921 & 0.951 & 0.952 & 0.663 & 0.695 & 0.994 & -0.675 \\
\hline $\mathrm{pH}$ & & & 1 & 1 & 0.888 & 0.904 & 0.866 & 0.862 & 0.845 & $-0.392^{*}$ \\
\hline TSS & & & & & 1 & 1 & 0.550 & 0.572 & 0.937 & -0.734 \\
\hline TDS & & & & & & & 1 & 1 & 0.589 & $0.062 *$ \\
\hline $\mathrm{Zn}$ & & & & & & & & & 1 & 1 \\
\hline
\end{tabular}

Correlation is significant at the 0.05 level (2-tailed)

${ }^{*} p>0.05$. No significant $p$ value

Table 9 Cross-validation criteria of empirical Bayesian kriging

\begin{tabular}{lll}
\hline Map name & $\begin{array}{l}\text { Mean standardized } \\
\text { error }\end{array}$ & $\begin{array}{l}\text { Standardized root } \\
\text { mean square error }\end{array}$ \\
\hline Ideal value & 0 & 1 \\
COD 2014 & 0.003 & 0.769 \\
pH 2014 & 0.012 & 0.884 \\
TSS 2014 & 0.002 & 0.850 \\
TDS 2014 & 0.016 & 0.963 \\
Zn 2014 & 0.007 & 0.819 \\
\hline
\end{tabular}

along Teesta area in case of COD, while it was greater along Rani Khola (from Singtam to Martam) in case of TSS. Change in $\mathrm{pH}$ weight led to a marginal change in WQSI value with almost $1 \%$ drop in WQSI value between Singtam and Martam. The slight decline in WQSI occurred all through the impact area with the rise in TDS weight. Moderate fall in WQSI value occurred with an increase in $\mathrm{Zn}$ weight. A fall of 5\% occurred along the Teesta area, while $4 \%$ fall occurred in the remaining impact area. On comparing Figs. 7 with 11, it can be inferred that a greater positive change rate was observed for areas with higher concentration of water pollutants like COD, while a greater negative change was observed for areas with a lower concentration of WQP like $\mathrm{Zn}$. These arguments are further emphasized using Fig. 12. It can be seen that an increase or decrease of $\mathrm{Zn}, \mathrm{COD}$, and TSS weight by $18 \%$ led to equal but opposite change in WQSI value. For instance, an increase in COD weight led to increase in change rate in areas with higher COD concentration, while a decrease in COD weight caused lower change rate in areas with higher COD concentration.

\section{Discussion}

One of the main objectives of this study was to perform an SWQIA for road-broadening-induced vehicular traffic increase. The study revealed that the traffic volume had a major effect on water pollution in the project impact area.
The major contributors to water pollution were COD, TSS, and to some extent $\mathrm{pH}$.

It was interesting to note that, as per the experts' opinion, heavy metal had the highest water pollutant weight, but actually, its contribution to water pollution was nominal in the impact area. This contradiction was also observed while comparing with other studies (Bingham et al. 2002). Estimates from the Empirical model partly support the previous studies. It showed that road runoff had a relatively higher concentration of COD and TSS, and it was relatively alkaline than the nearby rivers (USEP 1996; Gan et al. 2008). It is worth mentioning here that, traffic composition, high rainfall, and dense vegetation can be major players in mitigating traffic-induced heavy metal pollution in the study area (Hwang and Weng 2015; Schiff et al. 2016).

The mass balance model estimates were fairly close to the observed data. However, variations in the pollution profiles can be attributed to the higher instances of landslides, landuse change, or change in rainfall, which mass balance model is not equipped to predict. A significant correlation was observed between the water pollutants. This observation is in harmony with the previous studies (Bhandari and Nayal 2008; Waziri and Ogugbuaja 2010). The contrast of water pollutants in Teesta as compared to Rani Khola can be due to the construction of a number of small-to-medium hydel projects in Teesta such as in Dikchu area (DFEWM 2012). Satisfactory results of model validation criteria reinstate the reliability of mass balance model in SWQIA (Agrawal 2005). COD, pH, and TSS showed a higher concentration in Teesta. In terms of water quality, Teesta was much more polluted than Rani Khola. The abrupt transition of water quality at Martam and Singtam can be partly explained by relatively greater runoff contributed by large micro-catchments at specific points along the river. Moreover, the change in water quality at Singtam area was mainly due to the addition of large amount of COD and TSS into the impact area from Teesta. Cross-validation criteria of EBK showed satisfactory results validating the reliability of EBK. 
(a) Change in COD pollution level over the years
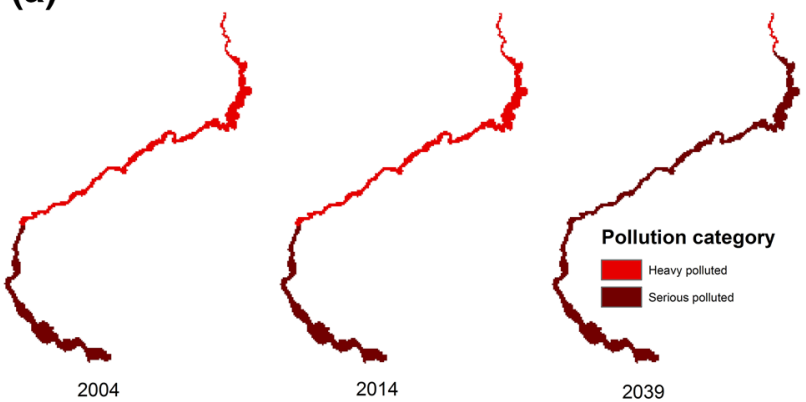

(c)

Change in TDS pollution level over the years

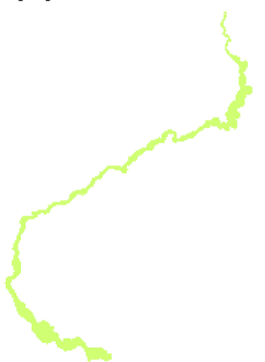

2004

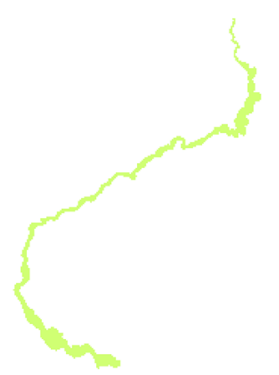

2014

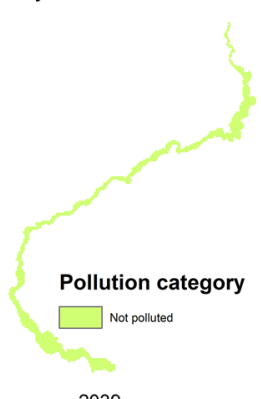

2039

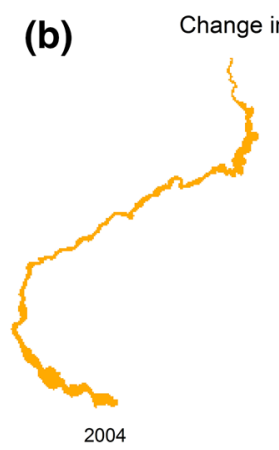

Change in $\mathrm{pH}$ pollution level over the years
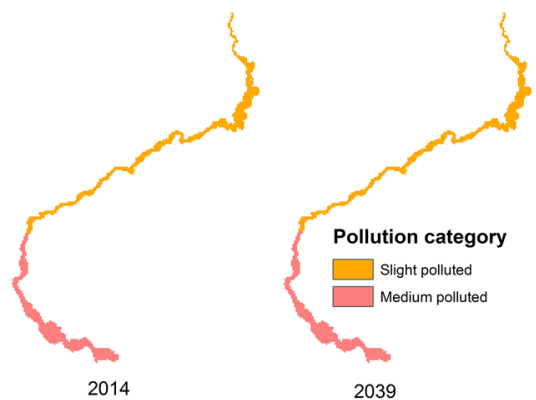

(d) Change in TSS pollution level over the years
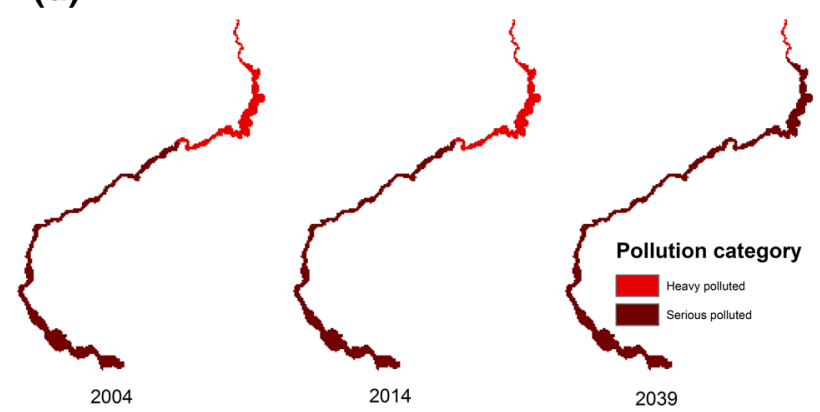

(e) Change in Heavy metal $(\mathrm{Zn})$ pollution level over the years

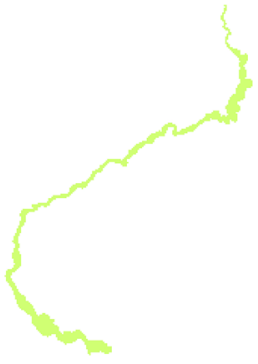

2004

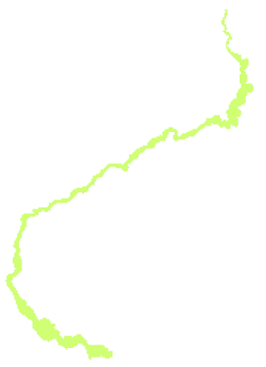

2014
Pollution category

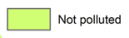

2039

Fig. 7 a Change in COD level under various project scenarios. b Change in pH level under various project scenarios. c Change in TDS level under various project scenarios. $\mathbf{d}$ Change in TSS level under various project scenarios. e Change in $\mathrm{Zn}$ level under various project scenarios

Fig. 8 Water quality status index maps of various project scenarios

\section{Change in WQSI value over the years}

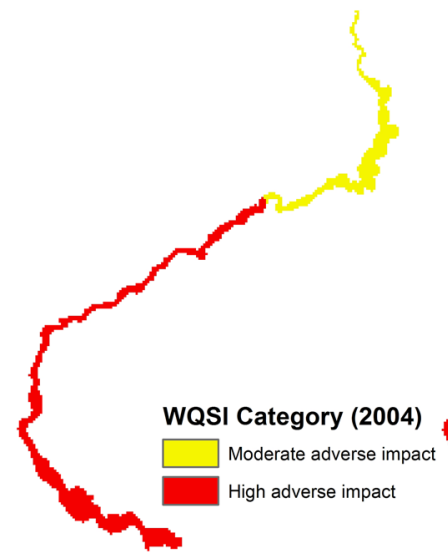

2004

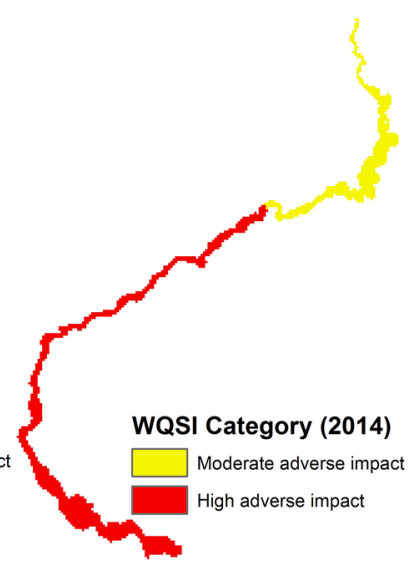

2014

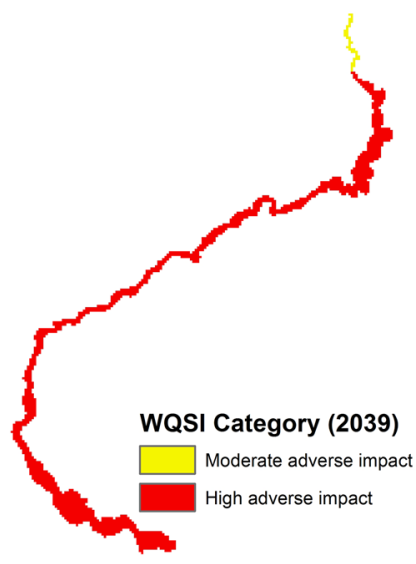

2039 
Fig. 9 Percent change in WQSI values a from pre-project to project implementation scenario. b From pre-project to the post-project scenario. c From project implementation to the post-project scenario
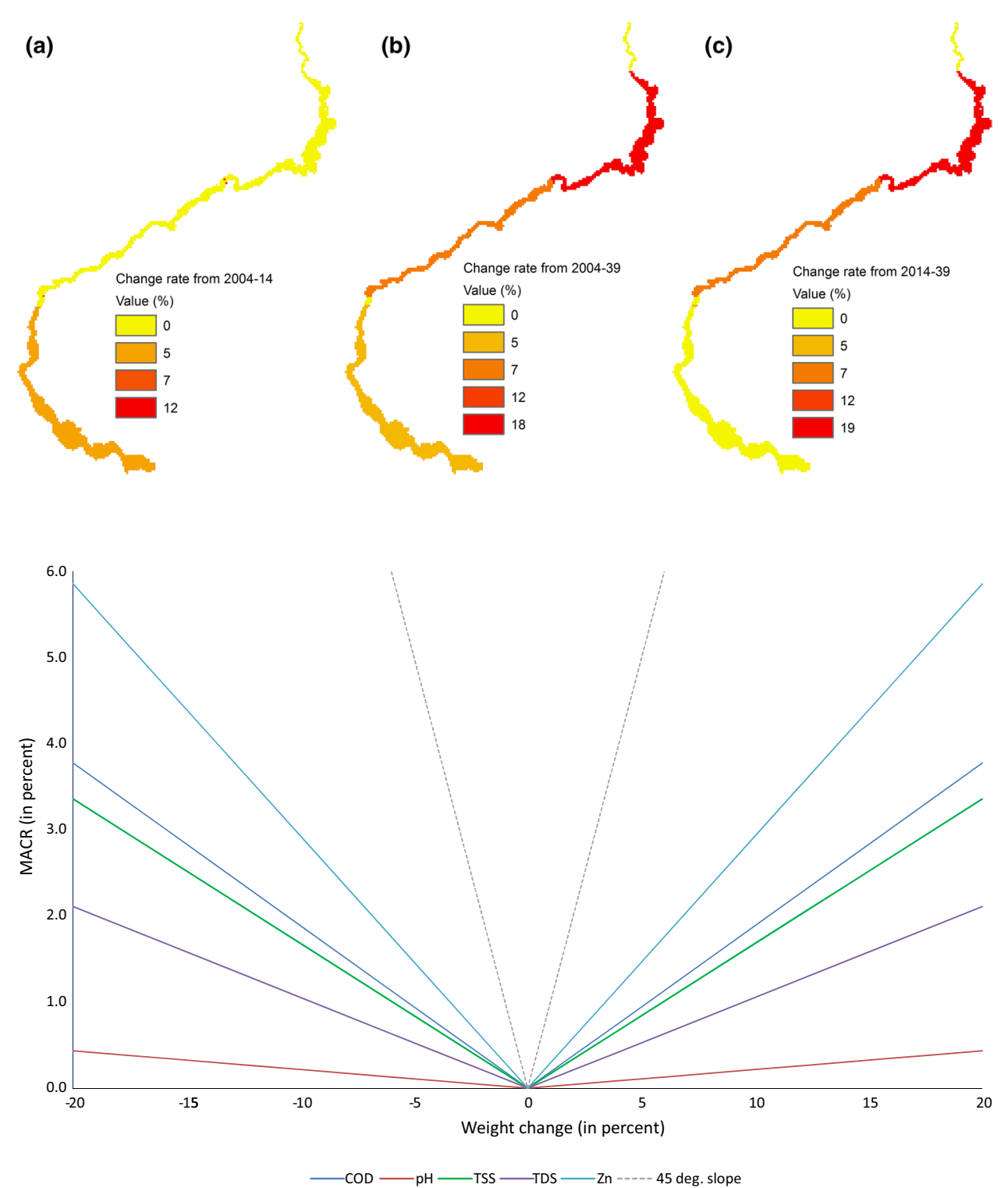

$-\mathrm{COD}-\mathrm{pH}-\mathrm{TSS} \longrightarrow \mathrm{TDS} \longrightarrow \mathrm{Zn}-----45 \mathrm{deg}$. slope
Fig. 10 MACR of WQSI over the change in water pollutant weights
The set of water pollutants considered in this study are widely accepted for the analysis of highway runoff (Agrawal et al. 2005; Venner 2004). However, a limited number of water pollutants and a relatively small stretch of highway were considered in the present study. A wider set of water pollutants including nutrients, metals, salts, BOD, and oil and grease can improve SWQIA model. Moreover, a wider acceptance of SWQIA model demands its validation for a wider study area like a longer road section or a network of roads. Although OAT is a relatively simple SA method, its application in the present study does highlight the role of criteria weight in overall spatial impact assessment. Such an attempt has not been made in earlier SWQIA studies. The MACR outcomes were in harmony with SESA method suggested by Xu and Zhang (2013). The similarity between priority order of criteria weight of AHP and slope of MACR, and gentle slopes of MACR $\left(\leq 45^{\circ}\right)$ showed the robustness of SWQIA model. Our study emphasized on SESA of criteria weight. However, it undermined the importance of SA of an attribute on the model (Chen et al. 2011). The present model used OAT, which is essentially a deterministic method of SA. Use of Monte Carlo simulation-based AHP can further add to the validity of the SESA method (Xu and Zhang 2013; Qi et al. 2013).

At present, hardly, any highway induced water pollution spatial models are available to serve for highway projects of developing countries, especially for hilly areas (Banerjee and Ghose 2016). Subjected to its validation in larger study areas and comprehensive water quality analysis, SWQIA model can be considered as a decision support tool for stakeholders in highway projects. Therefore, as to spatially 
Fig. 11 Change rate maps of WQSI due to increase in WQP weight by $16 \%$
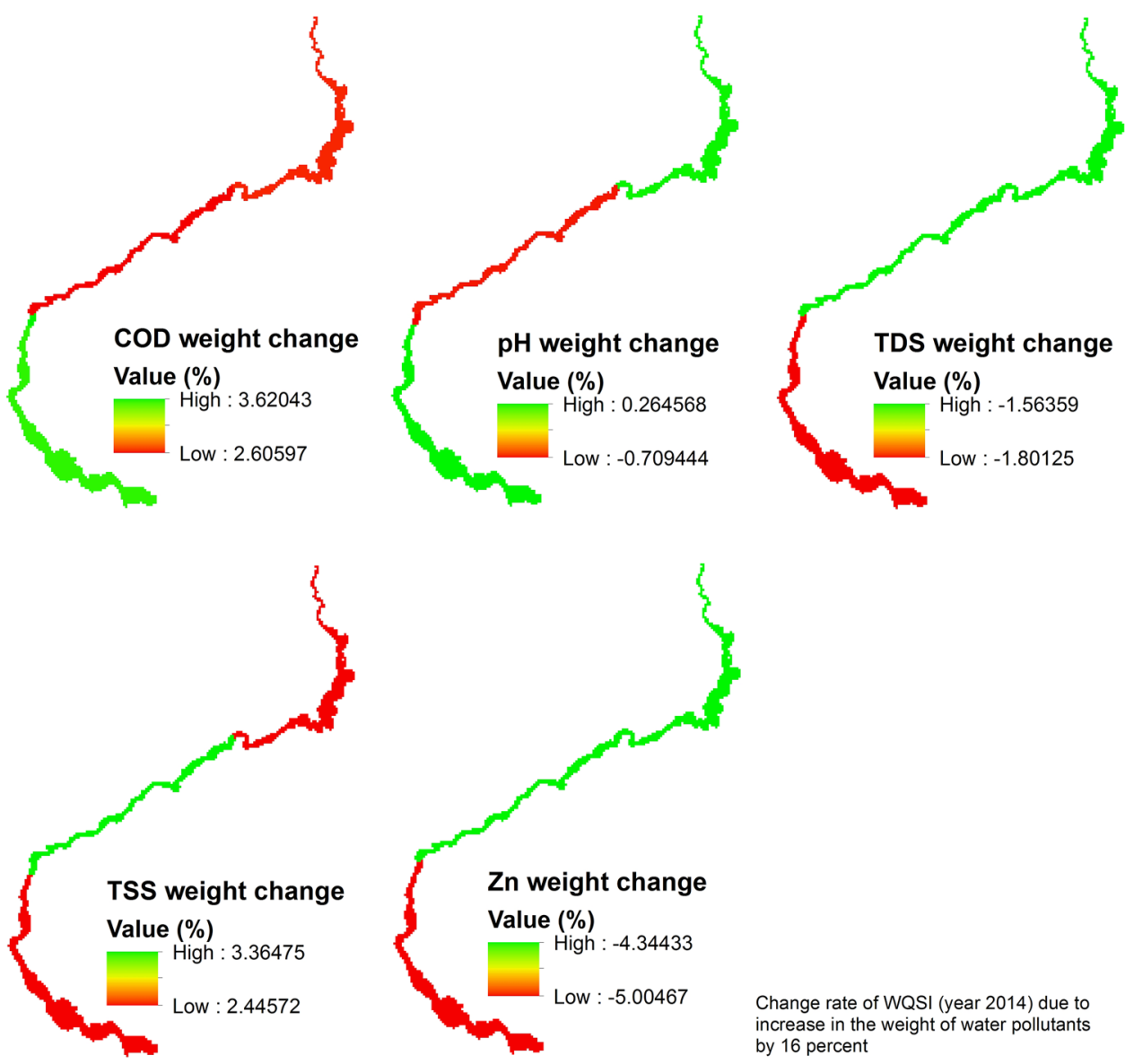

Change rate of WQSI (year 2014) due to increase in the weight of water pollutants by 16 percent visualize and interpret, the impacts of project-induced traffic volume change on the water quality in the vicinity of the highway. Moreover, SESA can be used as a reliable tool by the impact analyst to visualize the role of criteria weights and thereby incorporate people's and experts' perceptions into impact measurement and mitigation measures. With reliable spatial and temporal data, the present model can be used for a more refined SWQIA in similar areas.

\section{Conclusion}

Vehicular traffic is a significant contributor to water pollution to its nearby areas. SWQIA model suggested that water bodies as far as $500 \mathrm{~m}$ away from the highway can be affected by road runoff pollution. Spatial analysis of water quality impact due to highway projects in mountainous areas involved weighing of impact criteria and spatial impact classification. These are essential steps in combining and interpreting pollution impacts. These impacts showed high pollution level in the Teesta drainage area mainly due to $\mathrm{COD}, \mathrm{pH}$, and TSS. Temporal analysis showed that all the project scenarios had moderate-to-high adverse impact due to water pollution. SESA showed that the overall water quality summarized by WQSI was most sensitive to heavy metal weight followed by COD. Model validation and cross-validation criteria suggested that the model has a good predictive capability and spatial reliability in pollution prediction. This model can be further improved by more detailed meteorological and spatially distributed water quality data. The inclusion of stochasticity in criteria weighing along with attribute SA can substantiate the spatial explicit SA presented here. This SWQIA methodology can also be applied to other project impact analysis by selecting appropriate theoretical models for water pollutants measurement. AHP-based capturing of experts' as well as people's perception of impact criteria, geovisualization of impacts, temporal extrapolation of impacts, and SESA can substantially facilitate the decision support system of the project stakeholders.

Acknowledgements We thank Abhranil Adak, Assist. Prof., and Chandrashekhar Bhuiya, Professor, Dept. of Civil Engineering; and Santanu Gupta, Assist. Prof., School of Basic \& Applied Sciences, SMIT, Sikkim; Nirmalya Chatterjee, Associate, and Sunita Pradhan, Associate, 
Fig. 12 Change rate maps of WQSI value due to change in $\mathrm{Zn}, \mathrm{COD}$, and TSS weights by $\pm 18 \%$
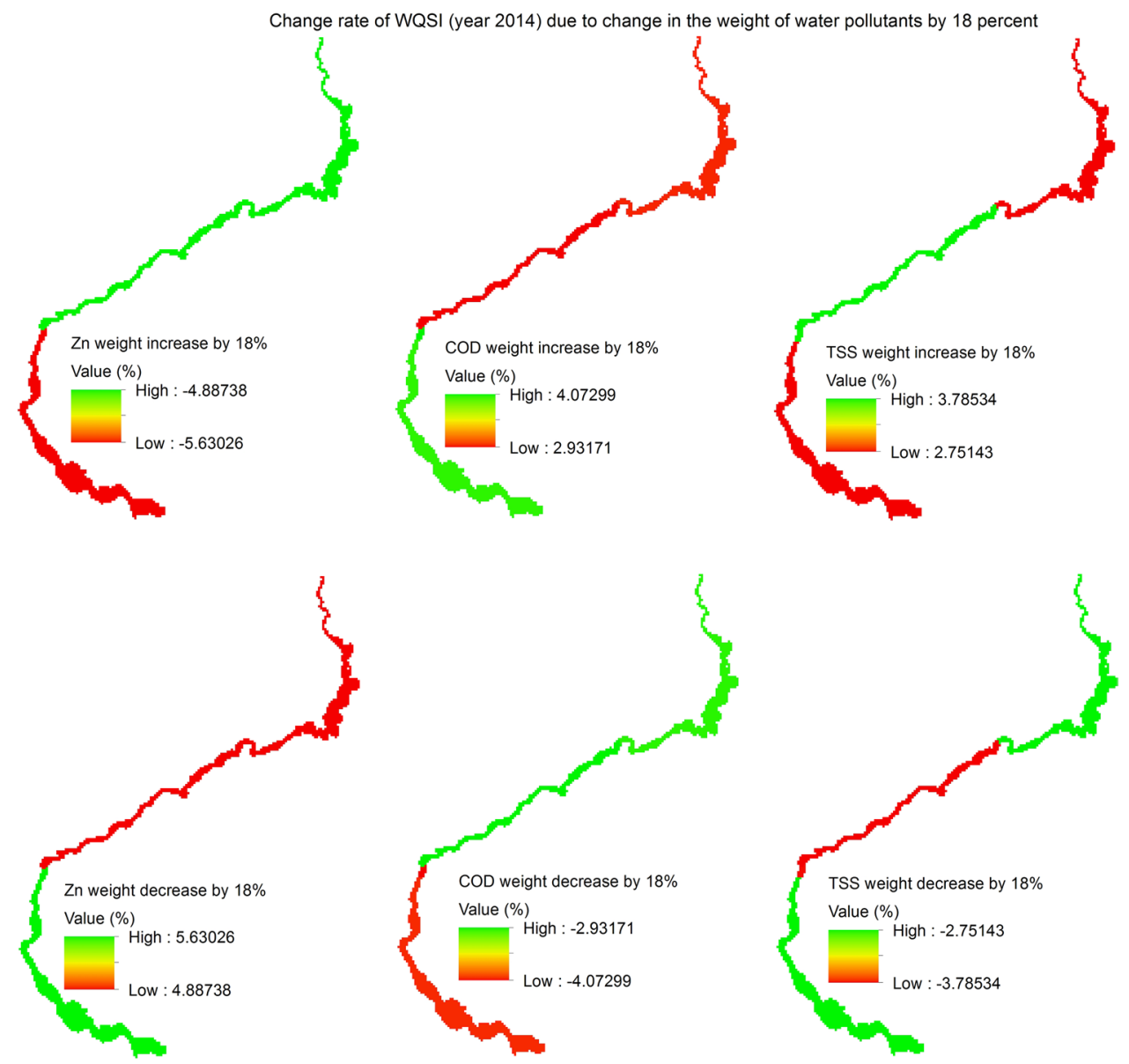

Aldheimer G, Bennerstedt K (2003) Facilities for treatment of stormwater runoff from highways. Water Sci Technol Journal Int Assoc Water Pollut Res 48(9):113-121

ATREE, Gangtok; Rakesh Ranjan, Associate Prof. Dept. of Geology, Sikkim University; and Sujata Subba, TGT Environment Sc., TNA, Gangtok for extending their expertise in this project.

\section{Compliance with ethical standards}

Conflict of interest No potential conflict of interest was reported by the authors.

Open Access This article is distributed under the terms of the Creative Commons Attribution 4.0 International License (http://creativeco mmons.org/licenses/by/4.0/), which permits unrestricted use, distribution, and reproduction in any medium, provided you give appropriate credit to the original author(s) and the source, provide a link to the Creative Commons license, and indicate if changes were made.

\section{References}

Agrawal ML (2005) A spatial quantitative approach for environmental impact assessment of highway projects. IIT, Khargpur

Agrawal ML, Maitra B, Ghose MK (2005) Spatial assessment of impacts on water quality due to highway development project. Asian J Water Environ Pollut 2(1):85-92
Antunes P, Santos R, Jordão L (2001) The application of Geographical Information Systems to determine environmental impact significance. Environ Impact Assess Rev 21(6):511-535. https:// doi.org/10.1016/S0195-9255(01)00090-7

Arrawatia PRMLE, Tambe S (2011) Biodiversity of Sikkim: exploring and conserving a global hotspot. Gangtok: Sikkim: Information and Public Relations Department. http://dspace.cus.ac.in/ jspui/handle/1/3028. Accessed 10 Jan 2018

Arriaza M, Nekhay O (2008) Combining AHP and GIS modelling to evaluate the suitability of agricultural lands for restoration. In Modelling agricultural and rural development polices, Sevilla

Banerjee P, Ghose MK (2016) Spatial analysis of environmental impacts of highway projects with special emphasis on mountainous area: an overview. Impact Assess Project Appraisal 34(4):279-293. https://doi.org/10.1080/14615517.2016.1176403

Banerjee P, Ghose MK (2017) A geographic information system-based socioeconomic impact assessment of the broadening of national highway in Sikkim Himalayas: a case study. Environ Dev Sustain 19(6):2333-2354. https://doi.org/10.1007/s10668-016-9859-7

Banerjee P, Ghose MK, Pradhan R (2016) GIS based spatial noise impact analysis (SNIA) of the broadening of national highway in Sikkim Himalayas: a case study. AIMS Environ Sci 3(4):714738. https://doi.org/10.3934/environsci.2016.4.714

Barthwal RR (2012) Environmental impact assessment, 2nd edn. New Age International Private Limited, New Delhi 
Bhandari NS, Nayal K (2008) correlation study on physico-chemical parameters and quality assessment of Kosi River Water, Uttarakhand [Research article]. https://doi.org/10.1155/2008/140986

Bhutia TY (2015) Biochemical properties of Teesta river system in Sikkim, M.Phil. Thesis, Dept. of Chemistry, School of Physical Sciences, Sikkim University, Gangtok

Bingham RL, Neal HV, El-Agroudy AA (2002) Characterization of the potential impact of storm runoff from highways on the neighbouring water bodies. Case-study: Tamiami trail project. In: 7th conference, Biennial stormwater research and watershed management, May 22-23, pp. 229-239

BIS (2012) Indian Standard Drinking Water-specification (Second Revision) IS 10500: 2012. Bureau of Indian Standards, Manak Bhavan, 9 Bahadur Shah Zafar Marg, New Delhi 110002

Brown AL, Affum JK (2002) A GIS-based environmental modelling system for transportation planners. Comput Environ Urban Syst 26(6):577-590. https://doi.org/10.1016/S0198-9715(01)00016-3

Canter L (1995) Environmental impact assessment, 2nd edn. McGrawHill, New York

Chang K-T (2017) Introduction to geographic information systems, 4th edn. McGraw Hill Education, New Delhi

Chen Y, Yu J, Khan S (2010) Spatial sensitivity analysis of multicriteria weights in GIS-based land suitability evaluation. Environ Model Softw 25(12):1582-1591. https://doi.org/10.1016/j.envso ft.2010.06.001

Chen H, Wood MD, Linstead C, Maltby E (2011) Uncertainty analysis in a GIS-based multi-criteria analysis tool for river catchment management. Environ Model Softw 26(4):395-405. https://doi. org/10.1016/j.envsoft.2010.09.005

CISMHE (2008a) Aquatic Environment and Water Quality in Carrying capacity of study of Teesta Basin in Sikkim- Volume VI, Biological Environment- Terrestrial and Aquatic Resources. Centre for Inter-Disciplinary Studies of Mountain \& Hill Environment, University of Delhi, Delhi

CISMHE (2008b) Land Environment- Soil in Carrying capacity of study of Teesta Basin in Sikkim- Volume III, Biological Environment- Terrestrial and Aquatic Resources. Centre for Inter-Disciplinary Studies of Mountain \& Hill Environment, University of Delhi, Delhi

Crosetto M, Tarantola S, Saltelli A (2000) Sensitivity and uncertainty analysis in spatial modelling based on GIS. Agr Ecosyst Environ 81(1):71-79. https://doi.org/10.1016/S0167-8809(00)00169-9

Cui H, Stein A, Myers DE (1995) Extension of spatial information, bayesian kriging and updating of prior variogram parameters. Environmetrics 6(4):373-384. https://doi.org/10.1002/env.3170060406

Davie T (2008) Fundamentals of hydrology, 2nd edn. Routledge, London

DFEWM (2012) Environmental Impact Assessment of Dikchu HE Project. Department of Forest, Environment and Wildlife Management, Government of Sikkim: Gangtok

Doamekpor L, Darko R, Klake R, Samlafo V, Bobobee L, Akpabli C, Nartey V (2016) Assessment of the contribution of road runoffs to surface water pollution in the New Juaben Municipality, Ghana. J Geosci Environ Prot 4:173-190. https://doi.org/10.4236/ gep.2016.41018

Fallahzadeh RA, Almodaresi SA, Dashti MM, Fattahi A, Sadeghnia M, Eslami H, Taghavi M (2016) Zoning of nitrite and nitrate concentration in groundwater using Geografic Information System (GIS), Case study: drinking water wells in Yazd City. J Geosci Environ Prot 04(03):91. https://doi.org/10.4236/gep.2016.43008

Feizizadeh B, Jankowski P, Blaschke T (2014) A GIS based spatiallyexplicit sensitivity and uncertainty analysis approach for multi-criteria decision analysis. Comput Geosci 64(Supplement C):81-95. https://doi.org/10.1016/j.cageo.2013.11.009
Flemming MJ, Doan JH (2013) HEC-GeoHMS Geospatial Hydrological Extension User's Manual Version 10.1. US Army Corps of Engineers

Forsyth AR, Bubb KA, Cox ME (2006) Runoff, sediment loss and water quality from forest roads in a southeast Queensland coastal plain Pinus plantation. For Ecol Manag 221(1):194-206. https:// doi.org/10.1016/j.foreco.2005.09.018

Gajendra C (2011) Water quality assessment and prediction modelling of Nambiyar river basin, Tamil Nadu. PhD thesis, Faculty of Civil Engineering, Anna University, Chennai 600025

Gan H, Zhuo M, Li D, Zhou Y (2008) Quality characterization and impact assessment of highway runoff in urban and rural area of Guangzhou, China. Environ Monit Assess 140(1-3):147-159. https://doi.org/10.1007/s10661-007-9856-2

Geneletti D (2004) Using spatial indicators and value functions to assess ecosystem fragmentation caused by linear infrastructures. Int J Appl Earth Obs Geoinf 5(1):1-15. https://doi.org/10.1016/j. jag.2003.08.004

Glasson J, Therivel R, Chadwick A (2005) Introduction to environmental impact assessment, 3rd edn. Routledge, London

Granato GE (2013) Stochastic empirical loading and dilution model (SELDM) version 1.0.0: U.S. Geological Survey Techniques and Methods, book 4, chap. C3, 112 p. U.S. Geological Survey, Reston, Virginia http://pubs.usgs.gov/tm/04/c03/. Accessed 27 June 2016

Gurung S, Subba S, Jha S, Pandey M (2015) Analysis of physic-chemical variations in water samples of river Teesta of Sikkim. Int J Eng Technol Res 2(2):49-60

Hwang C-C, Weng C-H (2015) Effects of rainfall patterns on highway runoff pollution and its control. Water Environ J 29(2):214-220. https://doi.org/10.1111/wej.12109

Karbassi AR, Mohammad Hosseini MF, Baghvand A, Nazariha M (2011) Development of Water Quality Index (WQI) for Gorganrood River. Int J Environ Res 5(4):1041-1046. https://doi. org/10.22059/ijer.2011.461

Kayhanian M, Singh A, Suverkropp C, Borroum S (2003) Impact of annual average daily traffic on highway runoff pollutant concentrations. J Environ Eng 129(11):975-990. https://doi.org/10.1061/ (ASCE)0733-9372(2003)129:11(975)

Kim L-H, Zoh K-D, Jeong S-M, Kayhanian M, Stenstrom MK (2006) Estimating pollutant mass accumulation on highways during dry periods. J Environ Eng 132(9):985-993. https://doi.org/10.1061/ (ASCE)0733-9372(2006)132:9(985)

Krivoruchko K (2012) Empirical bayesian kriging-implemented in ArcGIS Geostatistical Analyst. ArcUser. http://www.esri.com/ news/arcuser/1012/empirical-byesian-kriging.html

Kumar D, Alappat BJ (2009) NSF-water quality index: does it represent the experts' Opinion? Pract Period Hazard Toxic Radioact Waste Manag 13(1):75-79. https://doi.org/10.1061/ (ASCE) 1090-025X(2009)13:1(75)

Li M-H, Barrett ME (2008) Relationship between antecedent dry period and highway pollutant: conceptual models of buildup and removal processes. Water Environ Res 80(8):740-747. https://doi. org/10.2175/106143008X296451

Li Z, Fang Y, Zeng G, Li J, Zhang Q, Yuan Q, Ye F (2009) Temporal and spatial characteristics of surface water quality by an improved universal pollution index in red soil hilly region of South China: a case study in Liuyanghe River watershed. Environ Geol 58(1):101-107. https://doi.org/10.1007/s00254-008-1497-4

Lilburne L, Tarantola S (2009) Sensitivity analysis of spatial models. Int J Geogr Inf Sci 23(2):151-168. https://doi.org/10.1080/13658 810802094995

Lloyd C (2009) Spatial data analysis: an introduction for GIS users. OUP Oxford, Oxford

Longley PA, Goodchild M, Maguire DJ, Rhind DW (2010) Geographic information systems and science, 3rd edn. Wiley, Hoboken 
Machado ER, Junior do Valle RF, Sanches FLF, Pacheco FAL (2017) The vulnerability of the environment to spills of dangerous substances on highways: a diagnosis based on multi criteria modeling. Transp Res Part D Transp Environ. https://doi.org/10.1016/j.trd.2017.10.012

Merwade V (2012) Creating SCS curve number grid using HECGeoHMS. https://web.ics.purdue.edu/ vmerwade/education/cngri d.pdf. Accessed 12 Jan 2018

Murphy JM, Sexton DMH, Barnett DN, Jones GS, Webb MJ, Collins M, Stainforth DA (2004) Quantification of modelling uncertainties in a large ensemble of climate change simulations. Nature 430(7001):768-772. https://doi.org/10.1038/nature02771

Mushtaq F, Nee Lala MG, Pandey AC (2015) Assessment of pollution level in a Himalayan Lake, Kashmir, using geomatics approach. Int J Environ Anal Chem. https://doi.org/10.1080/03067 319.2015.1077517

Ohimain EI, Imoobe TO, Bawo DDS (2008) Changes in water physicchemical properties following the dredging of an oil well access canal in the Niger Delta. World J Agric Sci 4(6):752-758

Ostovari Y, Beigi Harchegani H, Davoodian AR (2012) Spatial variation of nitrate in the Lordegan Aquifer. Water Irrig Manag 2:55-67

Pagotto C, Legret M, Le Cloirec P (2000) Comparison of the hydraulic behaviour and the quality of highway runoff water according to the type of pavement. Water Res 34(18):4446-4454. https://doi. org/10.1016/S0043-1354(00)00221-9

Paliwal R, Srivastava L (2014) Policy Intervention Analysis: environmental impact assessment. The Energy and Resources Institute, TERI, New Delhi

Pilz J, Spöck G (2008) Why do we need and how should we implement Bayesian kriging methods? Stoch Env Res Risk Assess 22(5):621632. https://doi.org/10.1007/s00477-007-0165-7

Qi H, Qi P, Altinakar MS (2013) GIS-based Spatial Monte Carlo analysis for integrated flood management with two dimensional flood simulation. Water Resour Manag 27(10):3631-3645. https://doi. org/10.1007/s11269-013-0370-8

Rahman H, Karuppaiyan R, Senapati PC, Ngachan SV, Kumar A (2012) An analysis of past three-decade weather phenomenon in the mid-hills of Sikkim and strategies for mitigating possible impact of climate change on agriculture in Climate Change in Sikkim Patterns, Impacts and Initiatives. Information and Public Relations Department, Government of Sikkim, Gangtok

Saaty TL (1980) The analytic hierarchy process: planning, priority setting, resource allocation. Mcgraw-Hill, New York

Saaty TL (1990) How to make a decision: the analytic hierarchy process. Eur J Oper Res 48(1):9-26. https://doi.org/10.1016/03772217(90)90057-I

Saaty TL (2000) Fundamentals of decision making and priority theory with the analytic hierarchy process. RWS Publications, Pittsburg

Saaty TL, Vargas L (1994) Fundamentals of decision making and priority theory with the analytic hierarchy process: 6,1 st edn. Rws Pubns, Pittsburgh

Sadat-Noori SM, Ebrahimi K, Liaghat AM (2014) Groundwater quality assessment using the water quality index and GIS in SavehNobaran aquifer, Iran. Environ Earth Sci 71(9):3827-3843. https ://doi.org/10.1007/s12665-013-2770-8

Schiff KC, Tiefenthaler LL, Bay SM, Greenstein DJ (2016) Effects of rainfall intensity and duration on the first flush from parking lots. Water 8(8):320. https://doi.org/10.3390/w8080320

Siqueira HE, Pissarra TCT, Junior do Valle RF, Fernandes LFS, Pacheco FAL (2017) A multi criteria analog model for assessing the vulnerability of rural catchments to road spills of hazardous substances. Environ Impact Assess Rev 64:26-36. https://doi. org/10.1016/j.eiar.2017.02.002

Stenstrom MK, Silverman G, Bursztynsky TA, Zarzana AL, Salarz SE (1982) Oil and grease in stormwater runoff. Association of Bay Area Governments, Berkeley
Taha HA (2010) Operations research: an introduction, 9th edn. Pearson, Upper Saddle River

Takyi SA (2012) Review of Environmental Impact Assessment (EIA): approach, process and challenges. https://www.academia. edu/3703629/Review_of_Environmental_Impact_Assessment _EIA_Approach_Process_and_Challenges. Accessed 13 Oct 2017

Thomson NR, McBean EA, Snodgrass W, Monstrenko IB (1997) Highway stormwater runoff quality: development of surrogate parameter relationships. Water Air Soil Pollut 94(3-4):307-347. https ://doi.org/10.1007/BF02406066

Tong STY, Chen W (2002) Modeling the relationship between land use and surface water quality. J Environ Manag 66(4):377-393. https ://doi.org/10.1006/jema.2002.0593

USDA (2007) Hydrologic soil groups (Chapter 7) in hydrology national engineering handbook. 2007. https://www.nrcs.usda.gov/Inter net/FSE_DOCUMENTS/nrcs142p2_052731.pdf. Accessed 12 Jan 2018

USEP (1996) Indicators of the environmental impacts of transportation highway, rail, aviation, and maritime transport. U.S. Environmental Protection Agency, Policy, Planning, and Evaluation

USPH (1962) USPHS 956: Drinking Water Standards, US Public Health Service. The executive director office of the federal register, Washington DC

Venner M (2004) Identification of research needs related to highway runoff management. Transportation Research Board

Vojtek M, Vojteková J (2016) GIS-based approach to estimate surface runoff in small catchments: a case study. Quaestiones Geographicae 35(3):97-116. https://doi.org/10.1515/quageo-2016-0030

Waziri M, Ogugbuaja VO (2010) Interrelationships between physicochemical water pollution indicators: a case study of River YobeNigeria. Am J Sci Ind Res 1(1):76-80

Wu Jy S, Allan Craig J, Saunders William L, Evett Jack B (1998) Characterization and pollutant loading estimation for highway runoff. J Environ Eng 124(7):584-592. https://doi.org/10.1061/ (ASCE)0733-9372(1998)124:7(584)

Xu E, Zhang H (2013) Spatially-explicit sensitivity analysis for land suitability evaluation. Appl Geogr 45(Supplement C):1-9. https ://doi.org/10.1016/j.apgeog.2013.08.005

Yan C-A, Zhang W, Zhang Z, Liu Y, Deng C, Nie N (2015) Assessment of water quality and identification of polluted risky regions based on field observations and GIS in the Honghe River Watershed, China. PLoS One 10(3):e0119130. https://doi.org/10.1371/journ al.pone.0119130

Yannopoulos S, Basbas S, Andrianos TH, Rizos CH (2004) Receiving waters pollution investigation due to the interurban roads storm water runoff. In: Proceedings from the International Conference on Protection and Restoration of the Environment VII, Mykonos, Greece (CD)

Yannopoulos S, Basbas S, Giannopoulou I (2013) Water bodies pollution due to highways stormwater runoff: measures and legislative frameworks. Glob NEST J 15(1):85-92

Zhou F, Guo H, Liu Y, Hao Z (2007) Identification and spatial patterns of coastal water pollution sources based on GIS and chemometric approach. J Environ Sci 19(7):805-810. https://doi.org/10.1016/ S1001-0742(07)60135-1

Publisher's Note Springer Nature remains neutral with regard to jurisdictional claims in published maps and institutional affiliations. 